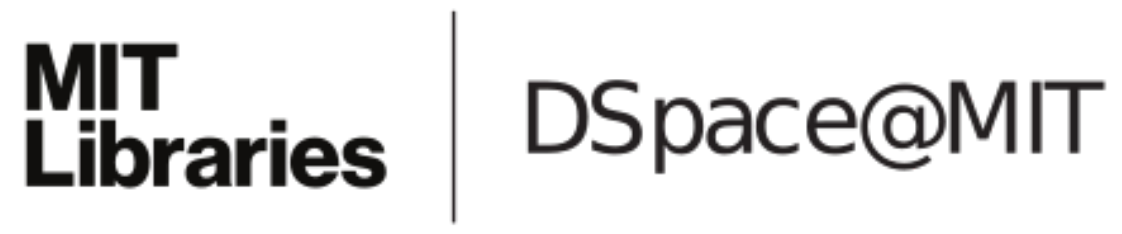

\author{
MIT Open Access Articles
}

Facile synthesis of carbon dots with superior sensing ability

The MIT Faculty has made this article openly available. Please share how this access benefits you. Your story matters.

As Published: https://doi.org/10.1007/s13204-018-0755-3

Publisher: Springer International Publishing

Persistent URL: https://hdl.handle.net/1721.1/131465

Version: Author's final manuscript: final author's manuscript post peer review, without publisher's formatting or copy editing

Terms of Use: Article is made available in accordance with the publisher's policy and may be subject to US copyright law. Please refer to the publisher's site for terms of use. 


\section{Facile synthesis of carbon dots with superior sensing ability}

Lin Jin, ${ }^{1}$ Jingguo Li, ${ }^{1}$ Liyun Liu, ${ }^{2 *}$ Zhenling Wang, ${ }^{3 *}$ Xingcai Zhang ${ }^{4,5^{*}}$

${ }^{1}$ Henan Provincial People's hospital, Zhengzhou University People's hospital,

Number 7 Weiwu road, Zhengzhou 450003, P. R. China

${ }^{2}$ Luoyang Orthopedic Hospital of Henan Province, Orthopedic Hospital of Henan Province, Zhengzhou, 45000 P. R. China

${ }^{3}$ Key Laboratory of Polymeric Composite \& Functional Materials of Ministry of Education, Sun Yat-sen University, Guangzhou, 510275, P. R. China

${ }^{4}$ School of Engineering, Massachusetts Institute of Technology, Cambridge, MA, 02139, USA

${ }^{5}$ John A. Paulson School of Engineering and Applied Sciences, Harvard University, Cambridge, Massachusetts, United States, 02138

*Corresponding authors.

E-mail address: liuliyunbs@126.com ; zlwang2007@ hotmail.com; xingcai@ mit.edu. Tel.: +86-394-8178518; +001-2253041387; Fax: +86-394-8178518. 
Abstract: Carbon dots (CDs) have various applications in biomedical and environmental field, such as bio-imaging, bio-sensing and heavy metal detection. In this study, a novel class of CDs were synthesized using a one-step hydrothermal method. The fabricated CDs displayed stable photoluminescence, good water-solubility, and photo-stability. Moreover, the functional groups (carboxylic acid moieties and hydroxyls) on the surface of the obtained CDs enable it with superior sensing ability (e.g. very low detectable concentration for $\mathrm{Pb}^{2+}: 5 \mathrm{nmol} / \mathrm{L}$ ). With superior detection sensitivity, excellent fluorescent properties and facile fabrication method, the as-obtained CDs can find practical applications as cost-effective and sensitive chemo-sensors in water and food safety field.

Keywords: carbon dots, hydrothermal method, photoluminescence, detection, $\mathrm{Pb}$

\section{Introduction}

Photoluminescent (PL) carbon-based materials with special nanoscale structures are attracting tremendous attention due to their excellent properties. ${ }^{1-8}$ The strong tunable luminescence has tunability further to improve these carbon nanomaterials versatile properties, thus, make them display great potential application in various filed, such as biological labeling, ${ }^{9-10}$ drug delivery, ${ }^{11}$ biological detection and imaging, ${ }^{12-16}$ optoelectronic devices, ${ }^{17-18}$ energy conversion. ${ }^{19-20}$ Recent years, various methods have been used to synthesize novel carbon-based nanomaterials. ${ }^{21-25}$ For example, CDs as one typical of the photoluminescent carbon-based nanomaterials have been developed due to its excellent optical absorptivity, chemical stability and water-soluble property. ${ }^{20}$ Given its outstanding performance, a series of methods have 
been developed to obtain CDs, such as laser ablation, ${ }^{26}$ chemical oxidation, ${ }^{27}$ electrochemical oxidation, ${ }^{28}$ and hydrothermal synthesis. ${ }^{29}$ However, the fabrication of the CDs with highly performance is still limited by the complexity of fabrication processes requiring specially designed equipment with expensive reagents/catalysts with severe and stringent synthesis conditions. Among these techniques, hydrothermal synthesis, a one-step method has attracted tremendous interest due to efficient yet facile process favorable for production of CDs in large quantities. ${ }^{30}$ However, the efficient one-step method for preparation of CDs with functional groups still persist to pose several challenges reinstating the need for more efficient synthesis protocols. Current preparation methods fail to effectively control lateral dimensions and surface chemistry. Further these methods often fail to deliver optimal fluorescent properties with high quantum yields (QY). Hence, there is a growing need for eco-friendly synthesis of CDs which could be exploited for novel applications.

With the development of industrial processes, there has been a surge in environmental heavy metal contamination in water, air, soil, and foods, which poses a serious health concern. As a typical heavy metal ion, $\mathrm{Pb}^{2+}$ with a very high toxicity has been observed to induce a variety of permanent damages for human and animal health, even at a low concentration range. Hence, ultrasensitive detection of $\mathrm{Pb}^{2+}$ ions is very critical for environmental protection and food safety. In this study, we synthesized CDs with a high density of functional groups on its surface by a facile and green route using a class of carbon source (citric acid, CA) and passivating agent (ethylenediaminetetraacetic acid disodium salt, EDTA-2Na). Furthermore, the 
synthesized fluorescent CDs could be designed as efficient C-based luminescent probes without the requirement of any complicated separation or further surface modification. $\mathrm{Pb}^{2+}$ was used as a candidate ion to evaluate the sensitivity of detection of the obtained CDs. Our results indicated that the obtained CDs have superior detection of $\mathrm{Pb}^{2+}$ even at a low concentration range. Equipped with outstanding fluorescent property and excellent water solubility, the developed CDs could be applied as a potential candidate in ultrasensitive detection field, such as heavy metal ions detection in the human body fluids, food safety and water environmental science.

\section{Experimental section}

\subsection{Preparation of CDs}

The CDs were synthesized by a hydrothermal method using novel carbon source (CA) and passivating agent (EDTA-2Na). Briefly, 0.02mM EDTA was dispersed in 100mL of $0.1 \mathrm{~mol} / \mathrm{L}$ citric acid solution then uniform mixed with absolute ethyl alcohol (VEt-oH :Vcitric acid $(a q)=1: 10)$. Then the mixture was transferred into a Teflon bottle, sealed and hydrothermally treated at $180^{\circ} \mathrm{C}$ for $7 \mathrm{~h}$. Then, the heated autoclave was cooled, and a light yellow solution was obtained. The solution was dialyzed by membrane based dialysis $(\mathrm{MWCO}=300)$ for $12 \mathrm{~h}$. Finally, CDs were recovered from the solution using concentrating the filtered solution treated by rotary evaporator.

\subsection{Detection of $\mathbf{P b}^{2+}$}

For $\mathrm{Pb}^{2+}$ detection, $30 \mathrm{mg}$ prepared $\mathrm{CDs}$ were dissolved in distilled water $(100 \mathrm{~mL})$. $5 \mathrm{~mL}$ CDs aqueous solution was added in a reagent bottle subsequently added the $\mathrm{Pb}^{2+}$ ion solution with various concentrations. The $\mathrm{Pb}^{2+}$ concentration was ranging from 5 
to $55 \mathrm{nmol} / \mathrm{L}$. The PL emission spectra $\left(\lambda_{\mathrm{ex}}=355 \mathrm{~nm}\right)$ were recorded after reaction between $\mathrm{Pb}^{2+}$ and the $\mathrm{CDs}(10 \mathrm{~min})$.

\subsection{Chemical and Structure Characterization}

The morphology of the prepared CDs was characterized using transmission electron microscopy (TEM, JEM-2010). The groups on the prepared CDs were examined by the Fourier transform infrared (FT-IR) spectrum (Bruker Co. Germany) was obtained in a $\mathrm{KBr}$ pellet, scanning from 4000 to $500 \mathrm{~cm}^{-1}$ wavelength range. Photoluminescence (PL) spectra and lifetime of the prepared CDs were recorded by an FLS920P Edinburgh Analytical Instrument apparatus, which equipped with a 450 W xenon lamp and the excitation sources was a F900H high-energy microsecond flash lamp.

\section{Results and discussion}

\subsection{Synthesis and Characterization of CDs}

The CDs were prepared by a hydrothermal method (as shown in Figure 1) using novel carbon source (CA) and passivating agent (EDTA-2Na), and have excellent optical absorptivity, chemical stability, and low toxicity. These unique properties make the prepared CDs be promising candidates for numerous practical applications, such as sensor, bio-imaging, medical diagnosis. In this study, the CDs were successfully prepared using the citric acid as the carbon source and the EDTA-2Na as the passivation agent.

The TEM image of the prepared CDs was shown in Figure $2 a$ and $2 b$, which indicated that the prepared CDs showed a uniform dispersion. Moreover, diameters of 
these prepared CDs were the range of 2 to $4 \mathrm{~nm}$, and the average size was $3.0 \mathrm{~nm}$. The high resolution TEM image (Figure 2c) displayed that the prepared CDs have good crystallinity. The results of the TEM images were clearly indicated that the prepared CDs can be well dispersed, and diameter has a narrow size distribution. Furthermore, the selected area electron diffraction pattern (inset in Figure 2c) obtained from the upper single CDs can be indexed to the (101), (112) and (011) planes. In addition, the prepared CDs showed excellent water-soluble and PL performance, as shown in the Figure 2 (d) and (e), respectively. The PL of the prepared CDs is much strong enough and could be seen by the naked eye.

The chemical characterization of the prepared CDs was tested by FT-IR and X-ray photoelectron spectroscopy (XPS). The functional groups of the prepared CDs were employed by FT-IR spectra (Figure 3a). The results indicate that numerous oxygen containing groups were clearly detected, the absorption peak of $-\mathrm{OH}$ was about $3432 \mathrm{~cm}^{-1}$, the peaks of $2912 \mathrm{~cm}^{-1}$ and $2834 \mathrm{~cm}^{-1}$ was corresponded to $-\mathrm{CH}_{2}-$ asymmetric and symmetric vibration respectively, and the vibrational absorption peak of $\mathrm{C}=\mathrm{O}$ was $1630 \mathrm{~cm}^{-1}$. In addition, the asymmetric stretching vibrations of $\mathrm{C}-\mathrm{NH}-\mathrm{C}$ were observed $\left(1114 \mathrm{~cm}^{-1}\right)$ and the bending vibrations of $\mathrm{N}-\mathrm{H}$ could also be observed $\left(1250 \mathrm{~cm}^{-1}\right)$. These results demonstrated that the prepared CDs were successfully modified by EDTA-Na, and abundant $-\mathrm{OH}$, epoxy, $-\mathrm{C}=\mathrm{O},-\mathrm{NH}$ and $-\mathrm{CH}$ groups were on the prepared CDs surface. ${ }^{31-32}$ The XPS spectra of prepared CDs are showed in Figure $3 \mathrm{~b}$, reveals the main characteristic peaks located at $532 \mathrm{eV}$ and $284 \mathrm{eV}$, which are assigned to $\mathrm{O} 1 \mathrm{~s}$ and $\mathrm{C} 1 \mathrm{~s}$ signals, respectively. Moreover, three main peaks of $\mathrm{C}$ 
atoms (Figure $3 \mathrm{~b}$ insert) of high-resolution $\mathrm{C} 1 \mathrm{~s}$ spectra displays the signal located at $284.6 \mathrm{eV}(\mathrm{C}-\mathrm{C}$ and $\mathrm{C}-\mathrm{H}),{ }^{33} 286.2 \mathrm{eV}$ (C-O-C, epoxide group) and $288.3 \mathrm{eV}(-\mathrm{COOH}$, carboxyl group), respectively. ${ }^{34}$ The results of XPS and FT-IR indicated a successful fabrication of CDs, and many functional groups on these CDs surface, such as the hydroxyl andcarboxyl groups. These functional groups make the prepared CDs have an excellent stability in water or organic solvent, thus making them to have enhanced capacity to detect of heavy metal ions in aqueous mediums. ${ }^{35-36}$ Optimal fluorescence is an important feature for the prepared CDs, which plays an important role for wide range of practical applications. The PL excitation and emission spectra were carried for further exploring the optical properties of the prepared CDs. The excitation and emission spectra of the prepared CDs (Figure 4a) showed a broad and symmetrical band with the maximum at $355 \mathrm{~nm}$ and $432 \mathrm{~nm}$, respectively, which was a typical luminescent feature of CDs. In addition, the PL decay profile of the prepared CDs displayed in Figure 4b, and the results indicated that PL decay curve could be well fitted into a single exponential function as:

$\mathrm{I}(\mathrm{t})=\mathrm{A}_{0} \exp \left(-\mathrm{x} / \tau_{1}\right)$

Thus, the corresponding lifetime was calculated by fitting to single exponential functions using iterative reconvolution, and the lifetime for CDs was determined to be 2.36ns.

\subsection{Detection of $\mathrm{Pb}^{2+}$ by Fluorescence Quenching of CDs}

As shown in FT-IR and XPS spectra, the as-prepared CDs contain a high density of carboxylic acid moieties and hydroxyls on their surface. Thus, these oxygen 
containing groups enhance the potential applicability for the heavy metal ions detection. In this study, we focused on the detection of $\mathrm{Pb}^{2+}$ by our as-prepared CDs. The detection based two factors: one is that $\mathrm{Pb}(\mathrm{OH})_{2}$ has a very low solubility product constant $\left(K \mathrm{sp}=1.2 \times 10^{-15}\right)$, which could make $\mathrm{Pb}^{2+}$ be easy to combine with hydroxyls on the prepared $\mathrm{CDs}$ surface of. Another is the combination between $\mathrm{Pb}^{2+}$ and EDTA $^{2-}$ groups caused the CDs aggregated and induced fluorescence quenching of CDs. The possible fluorescence quenching mechanism of the as-prepared CDs solution after addition of $\mathrm{Pb}^{2+}$ is shown in Figure 5. This demonstrated that the synergistic effects of these oxygen containing groups and EDTA2- could make CDs to effectively aggregate and achieve the optimal degree of fluorescence quenching, thereby exhibiting excellent detection sensitivity.

We use aqueous solution $(\mathrm{pH}=5)$ of the prepared $\mathrm{CDs}$ to detect various concentration of $\mathrm{Pb}^{2+}$, and evaluate the effect of $\mathrm{Pb}^{2+}$ concentration on the $\mathrm{PL}$ emission of prepared CDs solution. The results were shown in Figure 6, indicate that the PL performance of the prepared CDs with obvious quenching when at a $\mathrm{Pb}^{2+}$ concentration higher than $5 \mathrm{nmol} / \mathrm{L}$. However, the PL performance was not evidently obviously with decreasing the $\mathrm{Pb}^{2+}$ concentrations. This phenomenon could be attributed to two mainly possible factors regarding $\mathrm{Pb}^{2+}$ aggregation at low concentrations. Firstly, the carboxylic acid moieties on its surface of as-prepared CDs posed a limitation on the $\mathrm{Pb}^{2+}$ aggregation on $\mathrm{CD}$ surface. Secondly, EDTA ${ }^{2-}$ groups introduced into the CDs also play a very important role in $\mathrm{Pb}^{2+}$ aggregation. However, the $\mathrm{Pb}^{2+}$ could not have effective interaction with EDTA2- groups due to the cross 
interference with other groups at the $\mathrm{Pb}^{2+}$ concentration lower than $5 \mathrm{nmol} / \mathrm{L}$. These results strongly suggested that the determined concentration of CDs $(\mathrm{CCDs}=140 \mu \mathrm{g} / \mathrm{mL})$ could be only used in detecting $\mathrm{Pb}^{2+}$ within a certain acceptable range of concentration $(>5 \mathrm{nmol} / \mathrm{L})$. Furthermore, the fluorescence lifetime of prepared $\mathrm{CDs}$ solution after interaction with different concentration of $\mathrm{Pb}^{2+}$ has hardly any variation (Figure 7), which indicated that the quenching phenomenon followed a static progression. ${ }^{37-40}$

To further investigate the effect of $\mathrm{Pb}^{2+}$ concentration on the fluorescence properties of CDs solution, we studied the mutual influence between different concentrations of $\mathrm{Pb}^{2+}$ and $\mathrm{CDs}$. When the $\mathrm{Pb}^{2+}$ was added into the prepared CDs solution, the fluorescence of prepared CDs solution was subjected to quenching, which could be attributed to the interaction between $\mathrm{Pb}^{2+}$ and carboxylic groups. The results indicated that $\mathrm{Pb}^{2+}$ could potentially undermine the stability of the functional groups luminescence and reduce the aggregation of $\mathrm{CDs}$ in the solution. Figure 8a shows the fluorescence emission spectra of the prepared CDs aqueous solution with different concentration of $\mathrm{Pb}^{2+}$. These results indicated that the PL emission intensity of the prepared CDs solution was decreased with the $\mathrm{Pb}^{2+}$ concentration increasing.

The quenching of the fluorescence intensity by the $\mathrm{Pb}^{2+}$ could be calculated using the Stern-Volmer equation:

$\mathrm{F}_{0} / \mathrm{F}=1+\mathrm{K}_{\mathrm{sv}}\left[\mathrm{Pb}^{2+}\right]$

Where $\mathrm{F}_{0}$ is the fluorescence intensity without $\mathrm{Pb}^{2+}, \mathrm{F}$ is the fluorescence intensity obtained with the presence of the $\mathrm{Pb}^{2+}$ and $\mathrm{Ksv}$ is the Stern-Volmer (conductional 
stability) constant. The typical Stern-Volmer plot is shown in Figure 8b, which demonstrated that a calibration curve of $\mathrm{F}_{0} / \mathrm{F}=0.99+1.5 \times 10^{6}\left[\mathrm{~Pb}^{2+}\right]$ was obtained, and the concentration of $\mathrm{Pb}^{2+}$ was observed ( the range of concentration was 5 to 55 nmol/L). The minimum detection concentration of $\mathrm{Pb}^{2+}$ was measured, which was much lower compared to the maximum level of detection mentioned by the National Standard of China ( $24 \mathrm{nmol} / \mathrm{L})$, and also belows the permitted maximum level of the US Environmental Protection Agency (EPA).

In addition, we also evaluated the interactive effects at a higher concentration range between high concentrations of both $\mathrm{CDs}^{\mathrm{Pb}^{2+}}$ ions in aqueous solutions. The quenched response between of the prepared $\mathrm{CDs}$ solution and $\mathrm{Pb}^{2+}$ (Figure 9) indicated that the $\mathrm{CDs}$ have excellent detection sensitivity of $\mathrm{Pb}^{2+}$ at high concentration range. These results indicated that the prepared CDs could be potentially applied a sensor to detect $\mathrm{Pb}^{2+}$ in the body liquid or applied in other area, where detection of high concentration of $\mathrm{Pb}^{2+}$ is critical. ${ }^{41-50}$

\section{Conclusions}

In summary, we have developed a facile one-step and environmentally-friendly method to prepare CDs using novel carbon source (CA) and passivation agent (EDTA-2Na). The obtained CDs demonstrated good water-solubility, photo-stability and most importantly an ultrasensitive detection property for the detection of $\mathrm{Pb}^{2+}$ ions. It was found that the surface passivation agent EDTA-2Na plays a key role for the enhanced PL performance of carbon dots for metal ion detection. Moreover, the detailed study on interaction of $\mathrm{CDs}$ solution against $\mathrm{Pb}^{2+}$ at various concentration 
ranges indicate that the solution of $\mathrm{Pb}^{2+}$ quenched $\mathrm{CDs}$ could be used to detect $\mathrm{Pb}^{2+}$ at both very sparsely and highly concentrated solutions ( 5 to $55 \mathrm{nmol} / \mathrm{L}$ ). These results indicate that our CDs could hold a great potential to be suitably engineered for a wide range of heavy metal detection applications. We expect that this strategy can provide a new approach for developing a great variety of low cost and sensitive sensors for water detection and food safety applications.

\section{Acknowledgements}

The National Natural Science Foundation of China (Grant No: 51572303 and 21504082) supports this work. X. Zhang acknowledges the guidance from Prof. Mildred Dresselhaus. L. Jin acknowledges the program of Innovative Talent (in Science and Technology) in University of Henan Province (17HASTIT007).

\section{Notes}

The authors declare no competing financial interest.

\section{References}

1. Chung W, Jung H, Lee CH, Kim SH (2014) Extremely high color rendering white Light from Surface Passivated Carbon Dots and Zn-Doped AgInS 2 Nanocrystals. $J$. Mater. Chem. C 2: 4227-4232.

2. Schwenke AM, Hoeppener S, Schubert US (2015) Synthesis and Modification of Carbon Nanomaterials Utilizing Microwave Heating. Adv. Mater. 28: 4113-4141.

3. Gao XH, Lu YZ, Zhang RZ, He SJ, Ju J, Liu MM, Li L, Chen W(2015) One-pot synthesis of carbon nanodots for fluorescence turn-on detection of $\mathrm{Ag}^{+}$based on the $\mathrm{Ag}^{+}$-induced enhancement of fluorescence. J. Mater. Chem. C 3: 2302-2309.

4. Bao L, Liu C, Zhang ZL, Pang DW(2015) Photoluminescence-tunable carbon 
nanodots: surface-state energy-gap tuning. Adv. Mater 10: 1663-1667.

5. Jiang K, Sun S, Zahng L, Lu Y, Wu A, Cai CZ, Lin HW(2015) Red, green, and blue luminescence by carbon dots: full-color emission tuning and multicolor cellular imaging. Angew. Chem. Int. Edit. 18: 5360-5363.

6. Fernando KAS, Sahu S, Liu YM, Lewis WK, Guliants EA, Jafariyan A, Wang P, Bunker CE, Sun YP(2015) Carbon Quantum Dots and Applications in Photocatalytic Energy Conversion. ACS Appl. Mater. Interface 7: 8363-8367.

7. Liu JH, Cao L, LeCroy GE, Wang P, Meziani MJ, Dong Y, Liu Y, Luo PG, Sun YP(2015) Carbon "quantum" dots for fluorescence labeling of cells. ACS Appl. Mater. Interface 7: 19439-19445.

8. Fu M, Ehrat F, Wang Y, Milowska KZ, Reckmeier C, Rogach AL, Stolarczyk JK, Urban AS, Feldmann J(2015) Carbon dots: A unique fluorescent cocktail of polycyclic aromatic hydrocarbons. Nano Lett. 15: 6030-3035.

9. Wang W, Li YM, Cheng L, Cao ZQ, Liu WG(2014) Water-soluble and phosphorus-containing carbon dots with strong green fluorescence for cell labeling. J. Mater. Chem. B 2: 46-48.

10. Bruchez M, Moronne M, Gin P, Weiss S, Alivisatos AP(1998) Semiconductor nanocrystals as fluorescent biological labels. Science 281: 2013-2016.

11. Gogoi N, Chowdhury D(2014) Novel carbon dot coated alginate beads with superior stability, swelling and $\mathrm{pH}$ responsive drug delivery. J. Mater. Chem. B 2: 4089-4099.

12. Chong Y, Ma Y, Shen H, Tu X, Zhou X, Xu J, Dai J, Fan S, Zhang Z(2014) The 
in vitro and in vivo toxicity of graphene quantum dots. Biomaterials 35: $5041-5048$.

13. Chowdhuri AR, Tripathy S, Haldar C, Roy S, Sahu SK(2015) Single step synthesis of carbon dots embedded chitosan nanoparticles for cell imaging and hydrophobic drug delivery. J. Mater. Chem. B 3: 9122-9131.

14. Tan MQ, Zhang L, Tang R, Song X, Li Y, Wu H, Wang Y, Lv G, Liu W, Ma X(2013) Enhanced photoluminescence and characterization of multicolor carbon dots using plant soot as a carbon source. Talanta 115: 950-956.

15. Bhunia SK, Saha A, Maity AR, Ray SC, Jana NR(2013) Carbon nanoparticle-based fluorescent bioimaging probes. Sci. Rep. 3: 1473-1473.

16. Xu H, Li Q, Wang LH, He Y, Shi JY, Tang B, Fan CH(2014) Nanoscale optical probes for cellular imaging. Chem. Soc. Rev. 43: 2650-2661.

17. Mao LH, Tang WQ, Deng ZY, Liu SS, Wang CF, Chen S(2014) Facile access to white fluorescent carbon dots toward light-emitting devices. Ind. Eng. Chem. Res. 53: $6417-6425$.

18. Shen C, Wang J, Cao Y, Lu Y(2015) Facile Access to B-doped solid-state fluorescent carbon dots toward light emitting devices and cell imaging agents. $J$. Mater. Chem. C 3: 6668-6675.

19. Li HT, Kang ZH, Liu Y, Lee ST(2012) Carbon nanodots: synthesis, properties and applications. J. Mater. Chem. 22: 24230-24253.

20. Lzumi $Y(2013)$ Recent advances in the photocatalytic conversion of carbon dioxide to fuels with water and/or hydrogen using solar energy and beyond. 
Coordin. Chem. Rev. 257: 171-186.

21. Li HT, He XD, Kang ZH, Huang H, Liu Y, Liu JL, Lian SY, Tsang CHA, Yang $\mathrm{XB}$, Lee ST(2010) Water-soluble fluorescent carbon quantum dots and photocatalyst design. Angew. Chem. Int. Ed. 122: 4532-4536.

22. Mewada A, Pandey S, Thakur M, Jadhav D, Sharon M(2014) Swarming Carbon dots for folic acid mediated delivery of doxorubicin and biological imaging. $J$. Mater. Chem. B 2: 698-705.

23. Chandra S, Patra P, Pathan SH, Roy S, Mitra S, Layek A, Bhar R, Goswami A(2013) Luminescent S-doped carbon dots: an emergent architecture for multimodal applications. J. Mater. Chem. B 1: 2375-2382.

24. Wang WJ, Hai X, Mao QX, Chen ML, Wang JH(2015) Polyhedral oligomeric silsesquioxane functionalized carbon dots for cell imaging. ACS Appl. Mater. Interface 7: 16609-16616.

25. Yang ST, Gao L, Luo PG, Wang X, Wang H, Meziani MJ, Liu Y, Qi G, Sun YP(2009) Carbon dots for optical imaging in vivo. J. Am. Chem. Soc. 131:11308-11309.

26. Li HT, He XD, Liu Y, Huang H, Lian SY, Lee ST, Kang ZH(2011) One-step ultrasonic synthesis of water-soluble carbon nanoparticles with excellent photoluminescent properties. Carbon 49: 605-609.

27. Goncalves H, Jorge PAS, Femrnandes RAJ(2010) Hg(II) sensing based on functionalized carbon dots obtained by direct laser ablation. Sensors and Actuators B 145:702-707. 
28. Su YJ, Xie MM, Lu XN, Wei H, Geng HJ, Yang Z, Zhang YF(2014) Facile synthesis and photoelectric properties of carbon dots with upconversion fluorescence using arc-synthesized carbon by-products. $R C S A d v .4: 4839-4842$.

29. Zhou JG, Booker C, Li RY, Zhou XT, Sham T(2007) An electrochemical avenue to blue luminescent nanocrystals from multiwalled carbon nanotubes (MWCNTs). J. Am. Chem. Soc. 129: 744-745.

30. Oza G, Ravichandran M, Shinde S, Mewada A, Ramirez JT, Velumani S, Sharon M, Sharon M(2016) Camphor-mediated synthesis of carbon nanoparticles, graphitic shell encapsulated carbon nanotubes and carbon dots for bioimaging. Sci. Rep. 6: 21286-21286.

31. Dong YQ(2010) Extraction of electrochemiluminescent oxidized carbon quantum dots from activated carbon. Chem. Mater. 22: 5895-5899.

32. Jin L. Ren K, Xu QW, Hong TZ, Wu SY, Zhang YL, Wang ZL(2016) multifunctional carbon dots for live cell staining and tissue engineering applications. Polym. Composite. 2016, DOI: 10.1002/pc.23903.

33. Hu C, Zhai X, Liu L, Zhao Y, Jiang L, Qu L(2013) Spontaneous reduction and assembly of graphene oxide into three-dimensional graphene network on arbitrary conductive substrates. Sci. Rep. 3: 2065-2065.

34. Ganguly A, Sharma S, Papakonstantinou P, Hamilton J(2011) Probing the thermal deoxygenation of graphene oxide using high-resolution in situ X-ray-based spectroscopies. J. Phys. Chem. C 115: 17009-17019.

35. Zhang SR, Wang QG, Tian H, Ge HG(2014) A fluorescent turn-off/on method for 
detection of $\mathrm{Cu}^{2+}$ and oxalate using carbon dots as fluorescent probes in aqueous solution. Mater. Lett. 115: 233-236.

36. Yan FY, Zou Y, Wang M, Mu XL, Yang N, Chen L(2014) Highly photoluminescent carbon dots-based fluorescent chemosensors for sensitive and selective detection of mercury ions and application of imaging in living cells. Sensors and Actuators B: Chem. 192: 488-495.

37. Qin XY, Lu WB, Asiri AM, Al-Youbi AQ, Sun YP(2013) Green, low-cost synthesis of photoluminescent carbon dots by hydrothermal treatment of willow bark and their application as an effective photocatalyst for fabricating $\mathrm{Au}$ nanoparticles-reduced graphene oxide nanocomposites for glucose detection. Cata. Sci. tech. 3: 1027-1035.

38. Liu LQ, Li YF, Zhan L, Liu Y, Huang CZ(2011) One-step synthesis of fluorescent hydroxyls-coated carbon dots with hydrothermal reaction and its application to optical sensing of metal ions. Sci. China Chem. 54:1342-1347.

39. Wang F, Pang SP, Wang L, Li Q, Kreiter M, Liu CY(2010) One-step synthesis of highly luminescent carbon dots in noncoordinating solvents. Chem. Mater. 22: $4528-4530$.

40. Zeng HL, Durocher G(1995) Analysis of fluorescence quenching in some antioxidants from nonlinar stern-volmer plots. J. Lumin. 63: 75-84.

41. Vergaro V, Scarlino F, Bellomo C et al(2011). Drug-loaded polyelectrolyte microcapsules for sustained targeting of cancer cells. Adv. Drug Deliver. Rev. 63(9): 847-864. 
42. Du Y, Huang S, Wu S et al(2018). Preparation of versatile yolk-shell nanoparticles with a precious metal yolk and a microporous polymer shell for high-performance catalysts and antibacterial agents. Polymer 137:195-200.

43. Lin X, Liang Y, Lu Z et al(2017) Mechanochemistry: A green, activation-free and top-down strategy to high-surface-area carbon materials. ACS Sustain. Chem. Eng. 10:1021.

44. Niu Y, Stadler FJ, He T, Zhang X, Yu Y, Chen S(2017) Smart multifunctional polyurethane microcapsules for the quick release of anticancer drugs in BGC 823 and heLa tumor cells. J. Mater. Chem. B 5:9477.

45. Vergara D, Bellomo C, Zhang X, et al(2012) Lapatinib/paclitaxel polyelectrolyte nanocapsules for overcoming multidrug resistance in ovarian cancer.Nanomedicine: Nanotechnology, Biology, and Medicine 8: 891-899.

46. Pattekari P, Zheng Z, Zhang X, Levchenko T, Torchilin V, Lvov Y(2011) Top-down and bottom-up approaches in production of aqueous nanocolloids of low soluble drug paclitaxel. Physic. Chem. Chem. Physic. 13: 9014-19.

47. Lvov YM, Pattekari P, Zhang X, Torchilin V(2011) Converting poorly soluble materials into stable aqueous nanocolloids. Langmuir 27 (3): 1212-1217.

48 Zheng Z, Zhang X, Carbo D, Clark C, Nathan C, Lvov Y(2010) Sonication assisted synthesis of polyelectrolyte coated curcumin nanoparticles. Langmuir 26(11): 7679-7681.

49 Gong Z, Karandikar S, Zhang X, Kotipalli V, Lvov Y, Que L (2010) Composite nanomaterial thin film-based biosensors. IEEE Sensors, 29-32. 
50 Tian Y, Zhang X, Geng H, Yang H, Li C, Da S, Lu X, Wang J, Jia S (2017) Carbon nanotube/polyurethane films with high transparency, low sheet resistance and strong adhesion for antistatic application. RSC Advances 7 (83), $53018-53024$ 


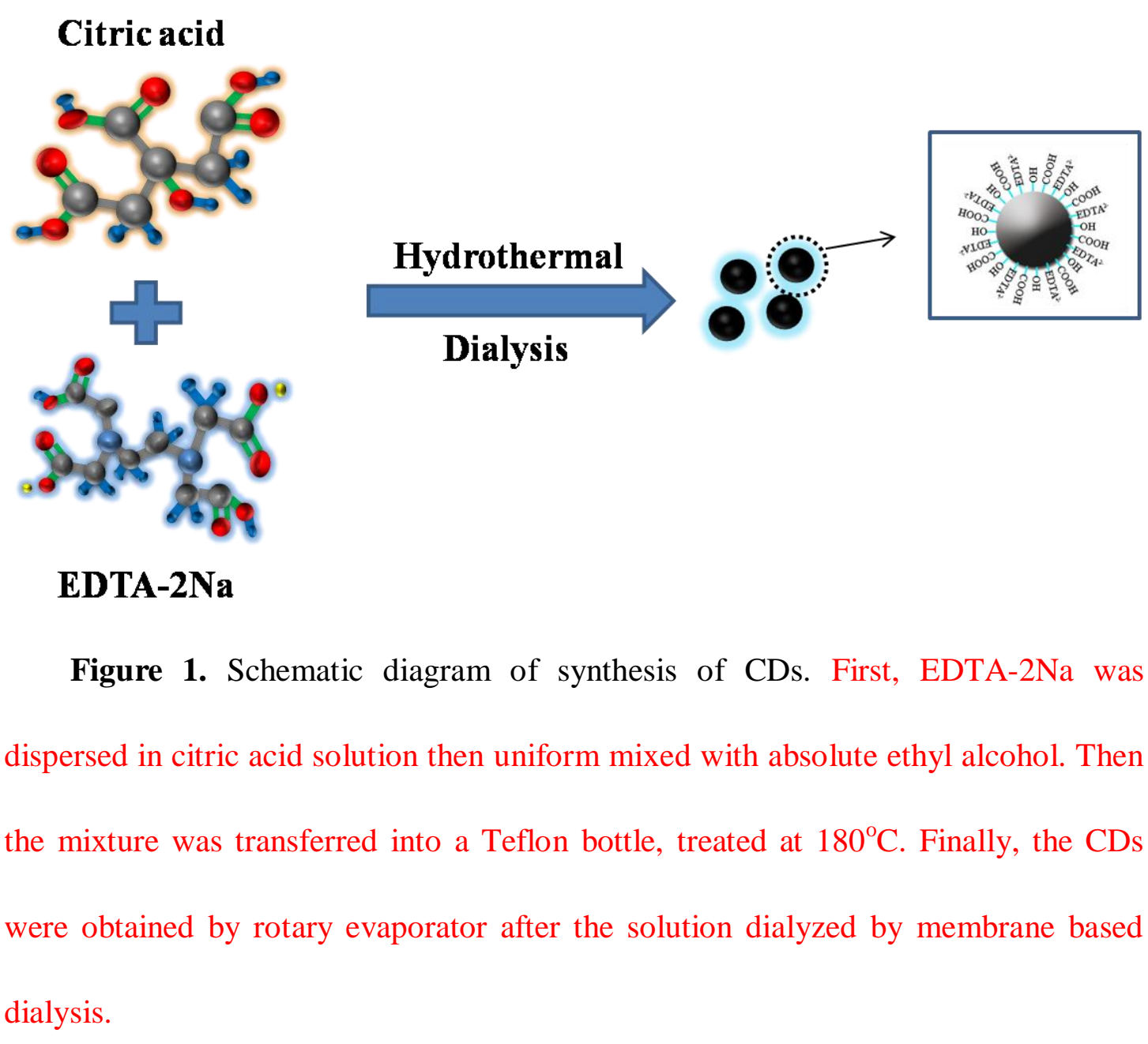




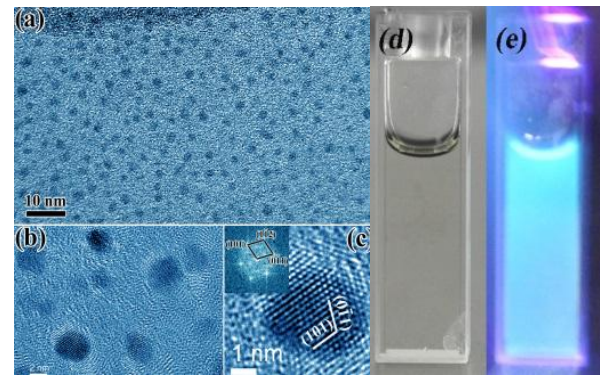

Figure 2. TEM images ( $a, b)$ and HRTEM image (c) of CDs, photographs of CDs dispersions in water with sunlight (d) and UV-light (365 nm, center) illumination (e). 

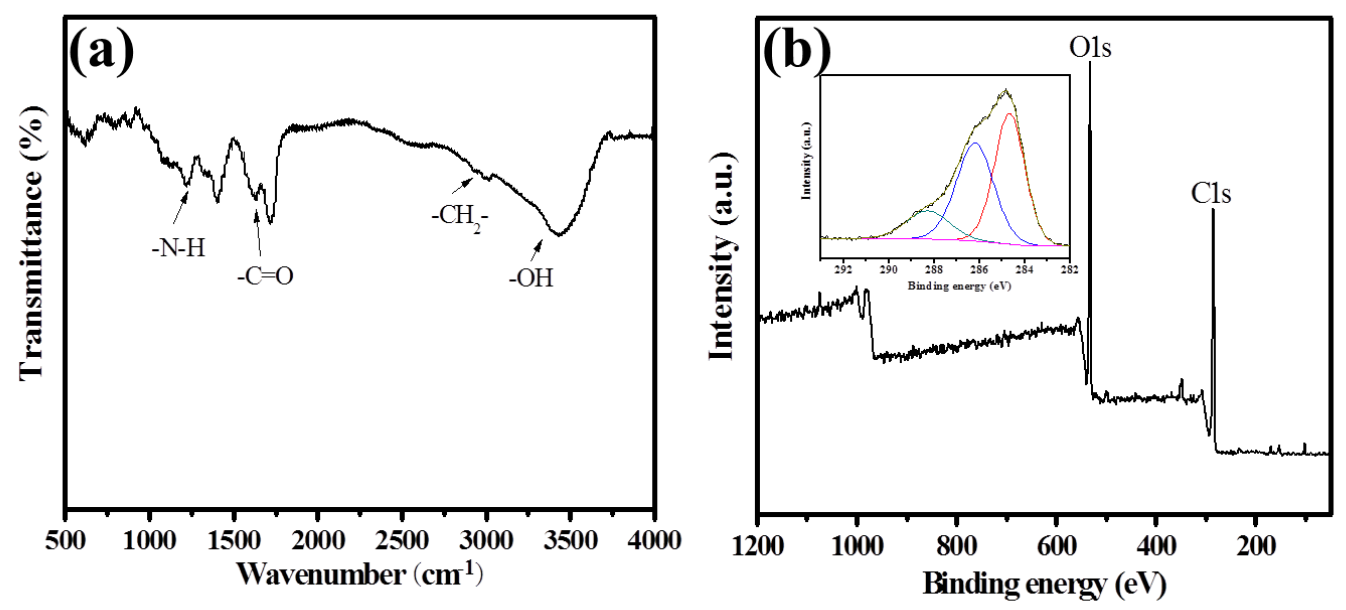

Figure 3. FT-IR spectrum (a) and XPS spectra (b) of the obtained CDs. 

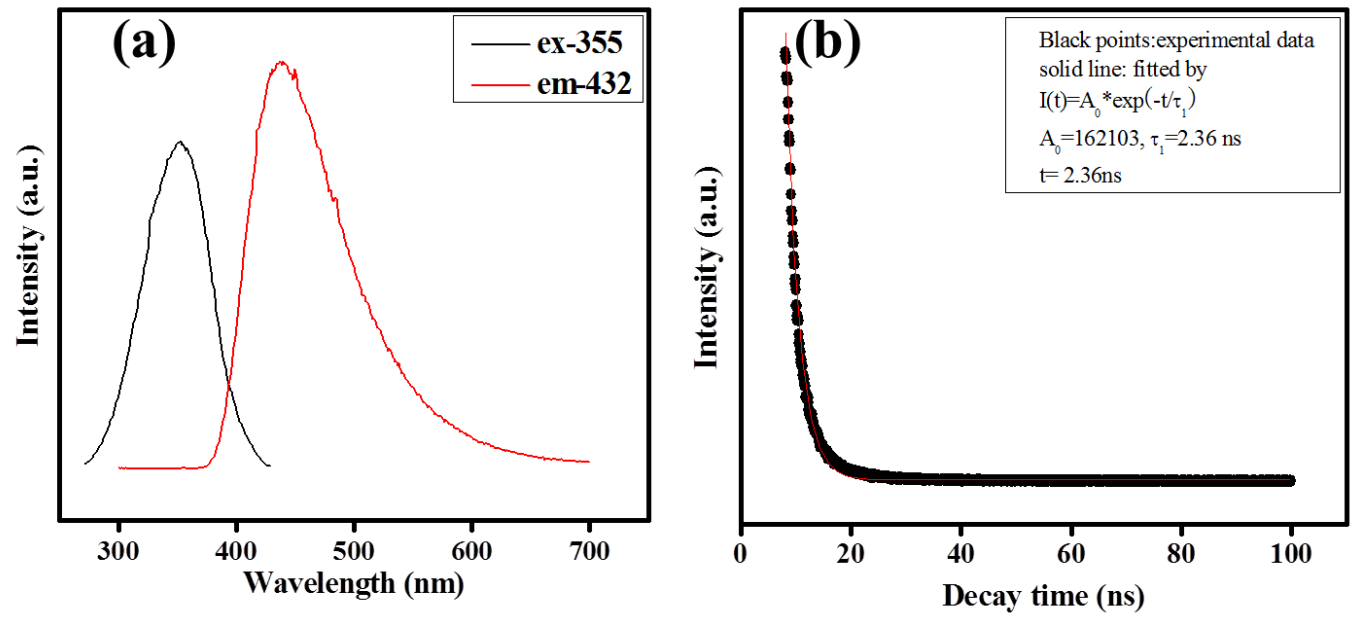

Figure 4. PL excitation (black line) and emission (red line) spectra (a) and the luminescent decay curve (b) of CDs in aqueous solution. 


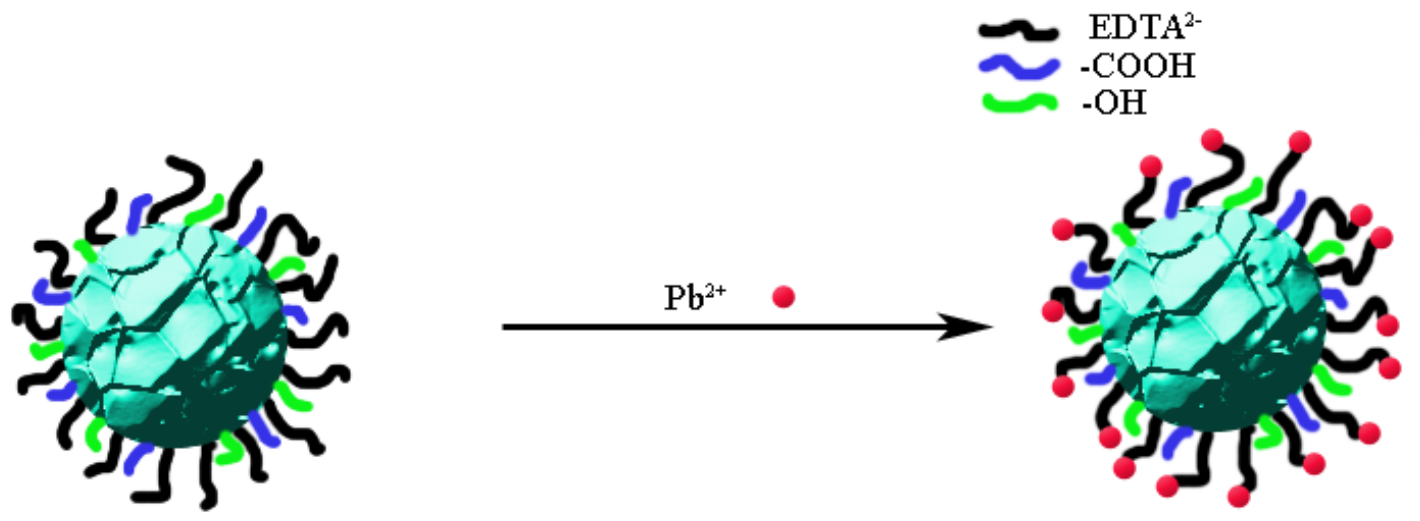

Figure 5. The fluorescence quenching mechanism of $\mathrm{CDs}$ was caused by $\mathrm{Pb}^{2+}$ by $\mathrm{CDs}$ aggregate. 


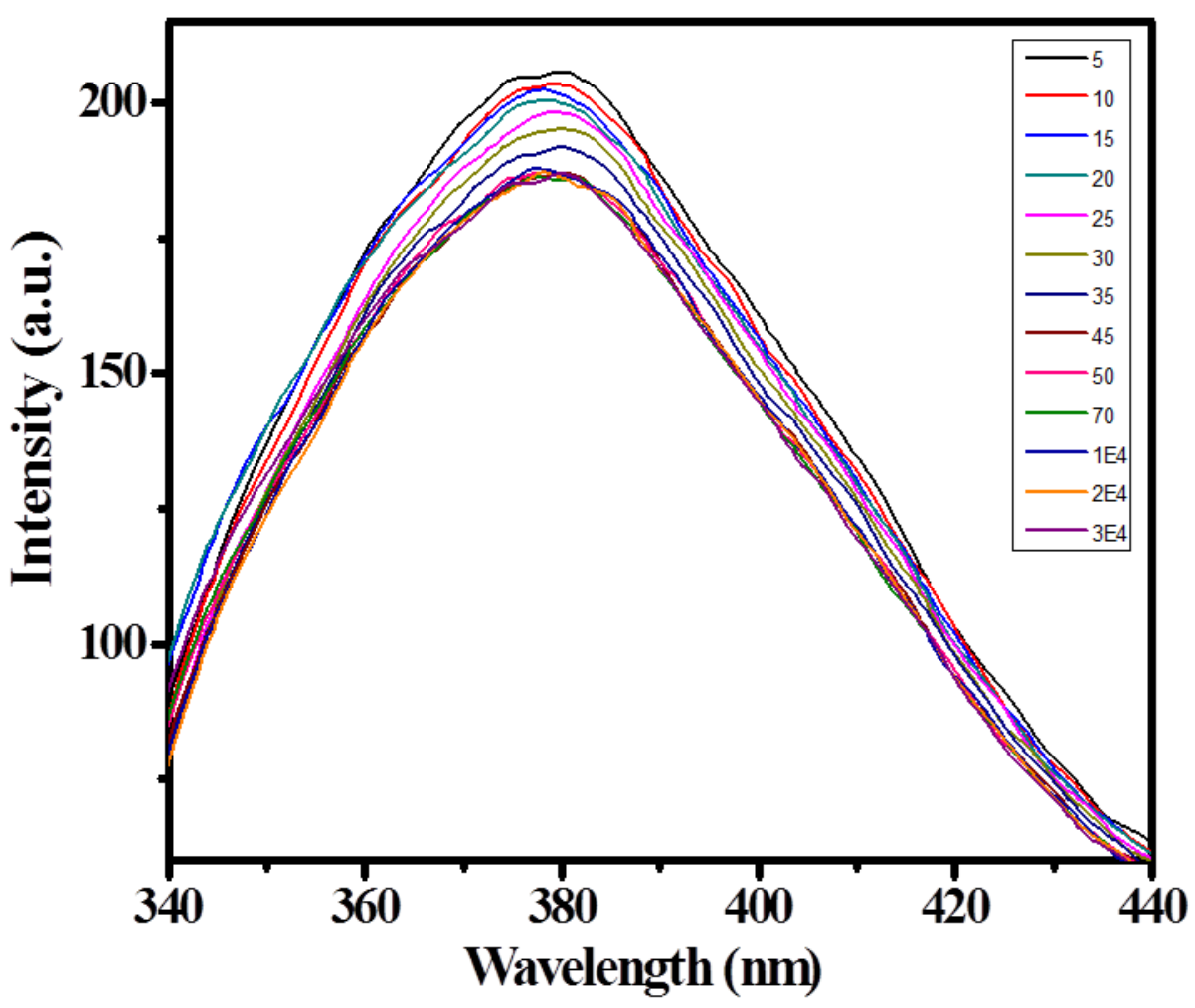

Figure 6. $\mathrm{PL}$ emission spectra of $\mathrm{CDs}$ aqueous solution $\left(\mathrm{C}_{\mathrm{CDs}}=140 \mu \mathrm{g} / \mathrm{mL}\right)$ with different concentrations of $\mathrm{Pb}^{2+} \cdot \mathrm{C}_{\mathrm{Pb}}{ }^{2+}: 5,10,15,20,25,30,35,45,50,70,1 \mathrm{E} 4,2 \mathrm{E} 4$, $3 \mathrm{E} 4 \mathrm{nmol} / \mathrm{L}\left(\lambda_{\mathrm{ex}}=310 \mathrm{~nm}\right.$, solution $\left.\mathrm{pH}=5\right)$. 

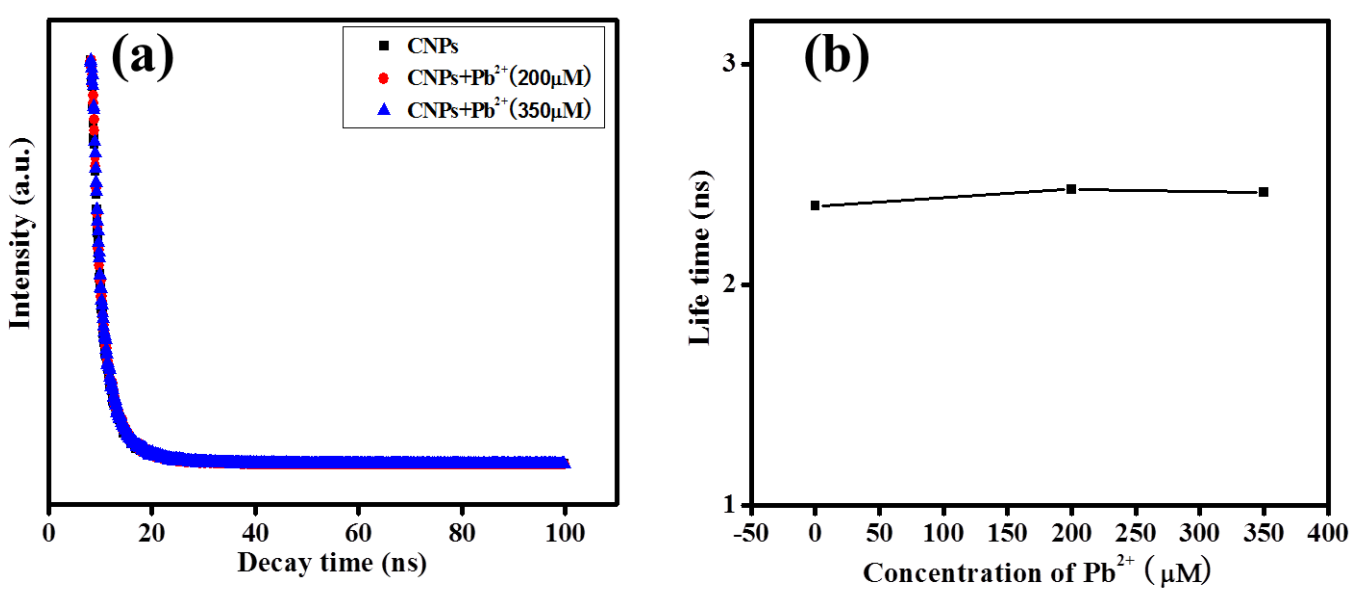

Figure 7. Fluorescence decay curves of pure CDs and CDs after their interaction with $200 \mu \mathrm{mol} / \mathrm{L}, 350 \mu \mathrm{mol} / \mathrm{L} \mathrm{Pb}^{2+}$ solution (a), the lifetime of CDs and CDs after their interaction with $\mathrm{Pb}^{2+}(\mathrm{b})$. 

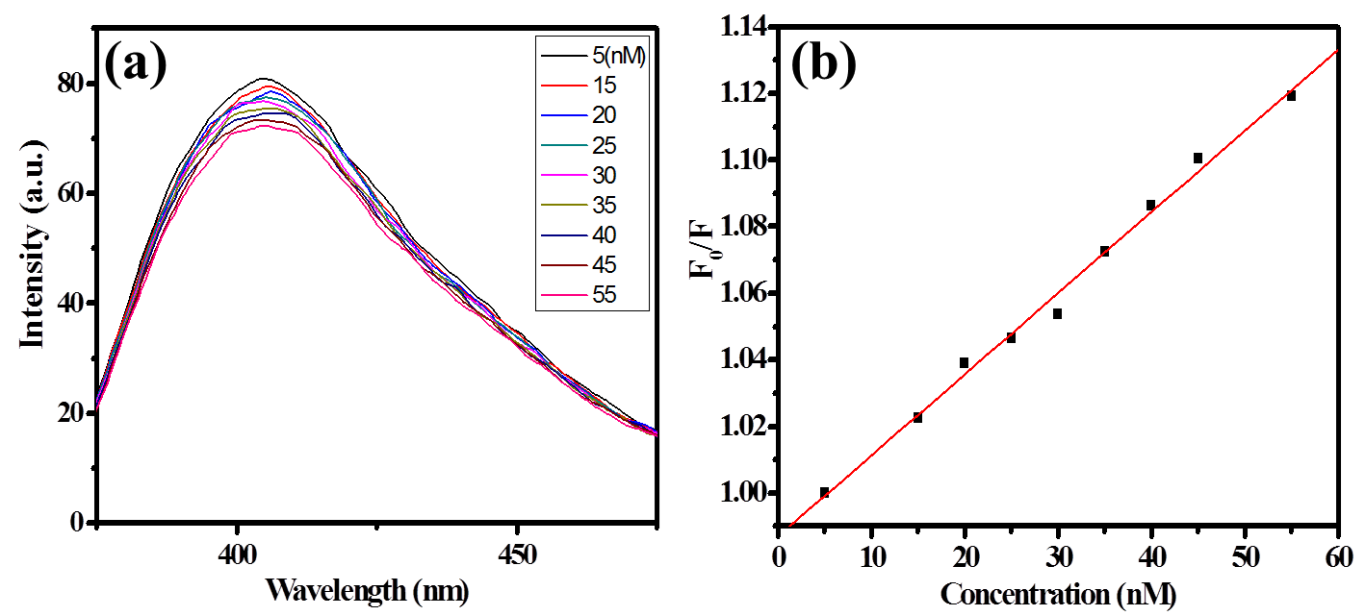

Figure 8. Fluorescence emission spectra of CDs aqueous solution after interaction with different concentrations of $\mathrm{Pb}^{2+}$ (a). $\mathrm{C}_{\mathrm{Pb}}{ }^{2+}: 5,15,20,25,30,35,40,45,55 \mathrm{nM}$ $\left(\mathrm{C}_{\mathrm{CDs}} 30 \mu \mathrm{g} / \mathrm{mL}\right.$, solution $\left.\mathrm{pH}=5, \lambda_{\mathrm{ex}}=310 \mathrm{~nm}\right)$. Stern-Volmer plots of the fluorescence quenching of $\mathrm{CDs}$ in aqueous solution by $\mathrm{Pb}^{2+}(\mathrm{b})$. 


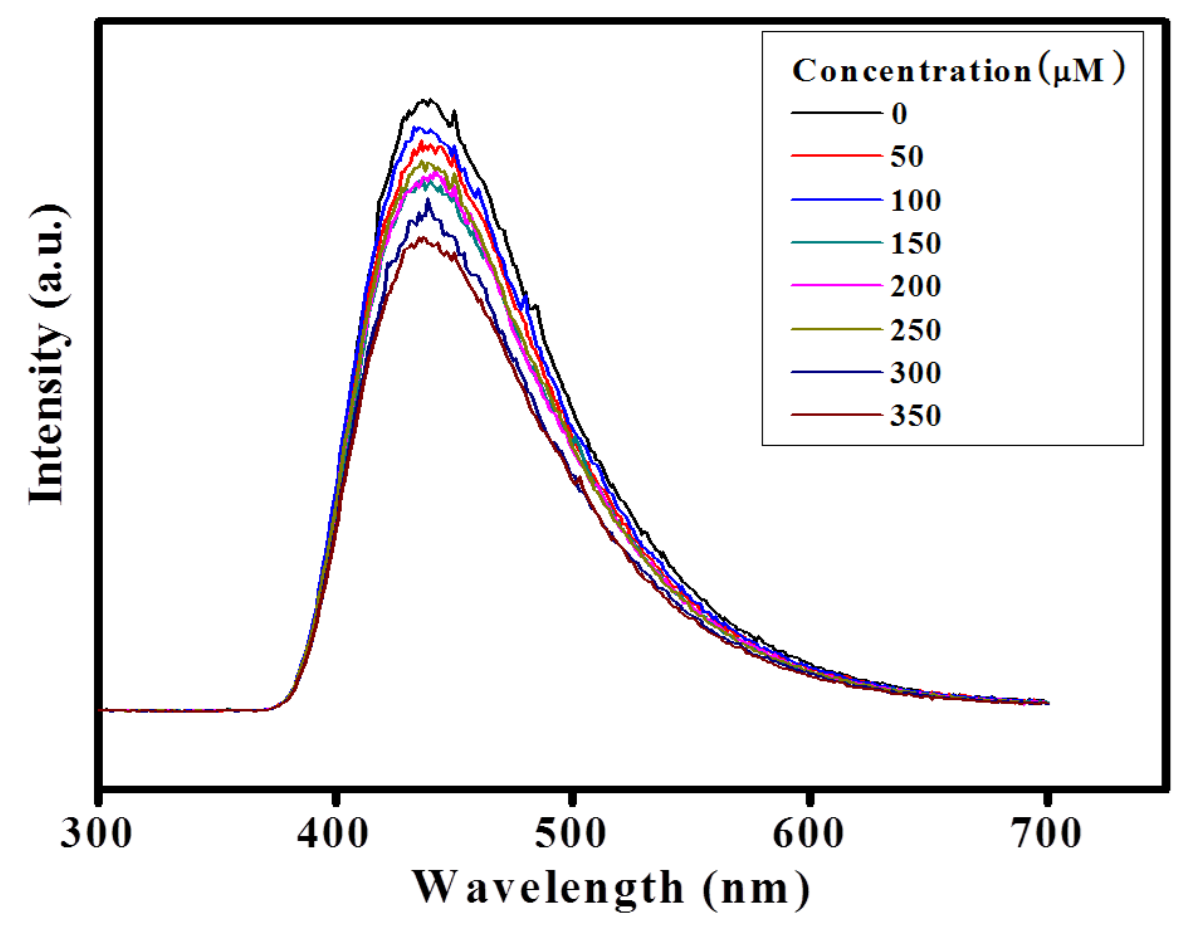

Figure 9. PL emission spectra of CDs $(140 \mathrm{mg} / \mathrm{mL})$ solution with various concentration of $\mathrm{Pb}^{2+}$ interaction. $\mathrm{C}_{\mathrm{Pb} 2+}: 0,50,100,150,200,250,300,350 \mu \mathrm{M}\left(\lambda_{\mathrm{ex}}\right.$ $=355 \mathrm{~nm}$, solution $\mathrm{pH}=6$ ).

\section{Supplementary Information}

\section{Facile synthesis of carbon dots with superior sensing ability}

Lin Jin, ${ }^{1}$ Jingguo Li, ${ }^{1}$ Liyun Liu, ${ }^{2 *}$ Zhenling Wang, ${ }^{3 *}$ Xingcai Zhang ${ }^{4,5}$ *

${ }^{1}$ Henan Provincial People's hospital, Zhengzhou University People's hospital,

Number 7 Weiwu road, Zhengzhou 450003, P. R. China

${ }^{2}$ Luoyang Orthopedic Hospital of Henan Province, Orthopedic Hospital of Henan Province, Zhengzhou, 45000 P. R. China

${ }^{3}$ Henan Key Laboratory of Rare Earth Functional Materials, Zhoukou 466001, P. R. China 
${ }^{4}$ School of Engineering, Massachusetts Institute of Technology, Cambridge, MA, 02139, USA

${ }^{5}$ John A. Paulson School of Engineering and Applied Sciences, Harvard University, Cambridge, Massachusetts, United States, 02138

*Corresponding authors.

E-mail address: liuliyunbs@126.com ; zlwang2007@hotmail.com; xingcai@mit.edu. Tel.: +86-394-8178518; +001-2253041387 Fax: +86-394-8178518. 


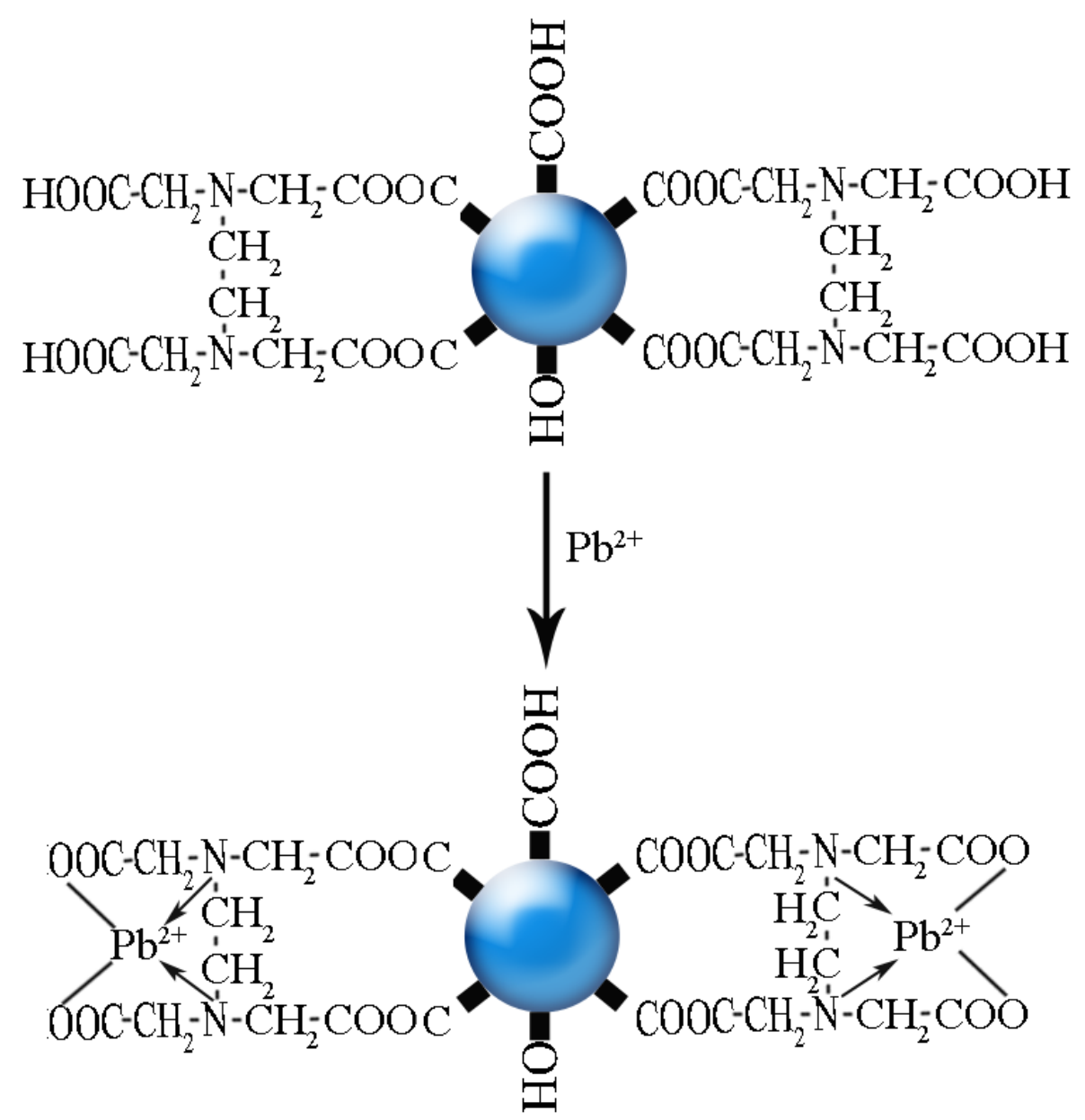

Fig. S1 The fluorescence quenching mechanism of EDTA ${ }^{2-}$ groups of the CDs was caused by $\mathrm{Pb}^{2+}$ aggregation on single CDs. 